\title{
SMOKING HABITS OF YOUNG SOLDIERS
}

BY

\author{
Lieutenant-Colonel H. J. A. RICHARDS, R.A.M.C., \\ AND \\ Major J. P. CROWDY, R.A.M.C. \\ From the Army School of Health
}

It is now generally accepted that cigarette smoking is a major contributory factor in the causation of lung cancer. Since smoking represents habituation, if not addiction, health education should be directed towards those who have not yet become addictedthe adolescent or the school child. Various studies of the smoking habits of school children of all ages have been made recently, but little is known of the habits of adolescents who have left school and not yet acquired the full adult habit of life. Most studies have been concerned with children of Secondary Modern, Grammar, or Public Schools (Raven, 1957; Parry Jones, 1957) and although the age groups surveyed ranged from 11-18 years, the number of boys over the age of 15 years has formed a very small proportion-less than 5 per cent. of the two major surveys carried out in Great Britain for which specific data are recorded (Bothwell, 1959; Chave and Schilling, 1959). In Norway, however, a survey of school children by Nilsen (1959) included 4,967 males between the ages of 13 and 20 years of whom 40 per cent. were aged 15 or over, whilst Todd (1959) gave figures, collected by random sampling in 1957 , of the smoking habits of young men aged 12 to 19 years.

A body of young men whose smoking habits could be the subject of accurate study is to be found in the young soldiers of the special training units which exist in the Army for those under the age of 18. In such a military population precise data of the total population at risk are obtainable thereby facilitating an accurate statistical study. A military population is also worthy of study in the light of figures given by the Tobacco Manufacturers for 1958, which indicate that, with an incidence of 70.6 per cent., male servicemen as a social group have the highest percentage of cigarette smokers in the community. Indeed, suggestions have been made from time to time that men in the Armed Services are encouraged to smoke cigarettes in conformity with their comrades, or as a result of the issue of free cigarettes in certain circumstances, and the provision of duty-free cigarettes overseas.

The Army Medical Services have recently started a programme of health education on smoking. Administrative medical officers have been instructed to make the facts of lung cancer known throughout the military community. Special efforts are to be made where the habit has not yet become fixed and Boy soldiers are picked out as the obvious target in this category. It was, therefore, considered that it would be of value to carry out a survey of the smoking habits of the young soldier at the start of this health education programme. The first aim would be to ascertain whether these boys, shortly to join a group which has the heaviest incidence of cigarette smoking, had the same smoking habits as their civilian counterparts or whether there was anything in the pattern of their smoking habits to assist or improve the efficiency of any campaign of health education. A secondary aim would be to establish a basis for the assessment of the efficacy of the education programme at some future date. In order that a direct comparison might perhaps be made with the schoolboy it was decided to follow the same pattern of survey as that used by the Study Group of the London School of Hygiene and Tropical Medicine (Chave and Schilling, 1959), and this we were able to do with only a little variation which was due to the different circumstances of the population with which we were concerned.

\section{Population}

Broadly speaking there are in the Army three categories of young soldier-the Apprentice Tradesman, the Junior Leader, and the Band Boy. The 
Junior Leader or the Band Boy is usually a secondary modern school boy who leaves school at the age of 15 and joins the Army; the Apprentice Tradesman is selected by competitive examination, at which only 30 per cent. of applicants are successful, and is probably the equivalent of the grammar school boy. However, both Apprentices and Junior Leaders differ from schoolboys of all categories in that they are paid a weekly wage from the time they first join their units. The customary joining age is from 15$16 \frac{1}{2}$, and at this stage they receive $£ 1186 \mathrm{~d}$. a week, rising at the end of the first year to $£ 256 \mathrm{~d}$. At $17 \frac{1}{2}$ they move on to a soldier's rates of pay, the starting point of which is just over $£ 5$ per week, but it should be noted that most of the units restrict the amount of cash the boys are given each week, putting a substantial sum into their savings. At 18 the Junior Leader transfers to man's service in a unit of the Regular Army, but the Apprentice may transfer rather later.

There are in the Army twelve Boy Units (as at November, 1959)—five Apprentice Schools teaching technical trades together with seven Junior Leader Units covering all arms of the Service and organized to produce a soldier who, although without a skilled trade, will become the senior NCO of the future.

\section{METHOD}

With the help of their Commanding Officers all these units were sampled. Table I shows the numbers of Apprentices and Junior Leaders, and give details of the percentage sampled. Out of a total of 5,682 only 4,381 questionnaires were collected, but it is most unlikely that any bias occurred at this stage. The fact that 872 Junior Leaders and 429 Apprentices could not be reached was due largely to such random events as sickness, absence on training, and similar military commitments. The figure of $8 \cdot 1$ per

TABLE I

DETAILS OF NUMBERS SAMPLED

\begin{tabular}{|c|c|c|c|}
\hline Subjects & $\begin{array}{c}\text { Appren- } \\
\text { tices }\end{array}$ & $\begin{array}{l}\text { Jun } \sigma \cdot r \\
\text { Leaders }\end{array}$ & Total \\
\hline $\begin{array}{lll}\ldots & \ldots & (a)\end{array}$ & 2,709 & 2,973 & 5,682 \\
\hline $\begin{array}{l}\text { Number of questionnaires completed } \\
\text { (b) }\end{array}$ & 2,280 & 2,101 & 4,381 \\
\hline $\begin{array}{l}\text { Number of completed questionnaires } \\
\text { accepted } \ldots \\
\begin{array}{l}\text {... } \\
\text {... }\end{array}\end{array}$ & 2,064 & 1,988 & 4,052 \\
\hline Percentage sample $\left(\frac{c}{a}\right) \times 100 \quad \ldots$ & $76 \cdot 2$ & 66.9 & $71 \cdot 3$ \\
\hline $\begin{array}{l}\text { Number of completed questionnaires } \\
\text { rejected } \ldots \\
\text {... }\end{array}$ & 216 & 113 & 329 \\
\hline Percentage rejected $\left(\frac{d}{b}\right) \times 100 \quad \ldots$ & 10.5 & $5 \cdot 7$ & $8 \cdot 1$ \\
\hline
\end{tabular}

cent. as a rejection rate for the completed questionnaires may be responsible for a slight bias towards a sample of above the average intelligence. The great majority of spoiled papers were due to the boys' inability to record their dates of birth correctly, nearly all in this category having put down the year 1959. It is likely that those who made this error were the ind ividuals of lowest intelligence, although on this basis one would expect the rejection rate for Junior Leaders to be higher than that for Apprentices, whereas, in fact, the reverse is the case.

\section{RESULTS}

Table II shows the percentage of Apprentices and Junior Leaders who had smoked by the age of 11 and who were regular smokers by the age of 13 . It will be seen that there is little difference between the Apprentice and the Junior Leader.

\section{TABLE II}

PERCENTAGE OF THOSE SAMPLED WHO HAD SMOKED BY THE AGE OF 11 AND BECAME REGULAR SMOKERS* BY THE AGE OF 13

\begin{tabular}{|c|c|c|c|}
\hline Subjects & $\begin{array}{l}\text { Appren- } \\
\text { tices }\end{array}$ & $\begin{array}{l}\text { Junior } \\
\text { Leaders }\end{array}$ & Total \\
\hline Had smoked by the age of 11 years & $22 \cdot 0$ & $21 \cdot 2$ & $21 \cdot 6$ \\
\hline 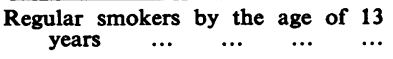 & $21 \cdot 1$ & $23 \cdot 7$ & $22 \cdot 4$ \\
\hline
\end{tabular}

i.e. one or more cigarettes per week.

Comparison with the surveys on school children has not been easy because the findings of these surveys were very varied. It would, however, be true to say that for these boys their first experience of smoking was in line with the findings of the civilian workers, and the number who had become regular smokers by the age of 13 , with the exception of one finding for grammar schoolboys, was less than in the case of the civilian school children. It must, however, be noted that, for one of the school surveys, a level of five or more cigarettes per week was taken as the criterion of smoking, instead of the figure of one or more cigarettes per week used by the other surveys including our own. It would seem that, relying on their memory of events which occurred some 2 to 6 years previously, the Army boys evidence on smoking habits before joining the Service was to the effect that they had their first experience of smoking at an age similar to their civilian counterparts but did not become regular smokers to the same extent.

We next compared the smoking habits of young soldiers during their service. Tables III and IV (opposite) show, for ages 15 to 18 years, details of those who 
regularly smoked cigarettes both for levels of one or more cigarettes per week and five or more cigarettes per week; together with the habits of regular smokers in terms of consumption per day.

It will be seen that the incidence of regular smoking, whether we take this to mean the smoking of more than one, or more than five, cigarettes per week rises from a level of 51 to 58 per cent. at age 15 to a level of 79 to 80 per cent. by the end of their Boy service; these latter levels being reached by Junior Leaders in their 18th and Apprentices in their 19th year. This increase is not regularly uniform over the years studied - the greatest rise takes place during the 16th year. In both Junior Leaders and Apprentices the increase during their 17th year is of the order of 15 to 20 per cent, whilst thereafter it is only 5 to 7 per cent. in any year, and this is true whichever criterion of "regular smoker" is applied. The 17th year is significant, too, in that by this age the difference between the two categories of regular smoker (i.e. more than one, or more than five, per week) becomes negligible.

Junior Leaders smoked to a greater extent than Apprentices, at equivalent ages, but only to the extent of 5 to 8 per cent., varying with age and type of regular smoker.

If we consider next the rate of consumption of cigarettes by the regular smokers it will be seen that once again the most striking change of habit occurs in the 17th year. During the 16th year there is a well-distributed scatter throughout the range of the amount smoked-between the limits of one to four per week and more than forty per week; and from reports of work done on school children, it would seem that this is also true for ages below 15 years. In their 17th year, however, the young soldiers' consumption of cigarettes, as recorded in Table IV, showed a marked "shift to the right" and there is an impressive drop in the percentage smoking only

TABLE III

PERCENTAGE OF BOYS WHO WERE REGULAR SMOKERS

\begin{tabular}{|c|c|c|c|c|c|c|c|c|c|}
\hline \multirow[b]{2}{*}{ Age (yrs) } & \multicolumn{3}{|c|}{ Apprentices } & \multicolumn{3}{|c|}{ Junior Leaders } & \multicolumn{3}{|c|}{ Total } \\
\hline & $\begin{array}{l}\text { No. in } \\
\text { Age } \\
\text { Group }\end{array}$ & $\begin{array}{c}\text { Percentage } \\
\text { smoking more } \\
\text { than one } \\
\text { per week }\end{array}$ & $\begin{array}{c}\text { Percentage } \\
\text { smoking more } \\
\text { than five } \\
\text { per week }\end{array}$ & $\begin{array}{l}\text { No. in } \\
\text { Age } \\
\text { Group }\end{array}$ & $\begin{array}{c}\text { Percentage } \\
\text { smoking more } \\
\text { than one } \\
\text { per week }\end{array}$ & $\begin{array}{c}\text { Percentage } \\
\text { smoking more } \\
\text { than five } \\
\text { per week }\end{array}$ & $\begin{array}{l}\text { No. in } \\
\text { Age } \\
\text { Group }\end{array}$ & $\begin{array}{c}\text { Percentage } \\
\text { smoking more } \\
\text { than one } \\
\text { per week }\end{array}$ & $\begin{array}{l}\text { Percentage } \\
\text { smoking more } \\
\text { than five } \\
\text { per week }\end{array}$ \\
\hline $15-$ & 345 & $54 \cdot 2$ & $46 \cdot 6$ & 431 & $61 \cdot 7$ & 54.9 & 776 & $58 \cdot 4$ & $51 \cdot 3$ \\
\hline $16-$ & 693 & $70 \cdot 4$ & 66.9 & 825 & $75 \cdot 1$ & $72 \cdot 2$ & 1,518 & $73 \cdot 1$ & $69 \cdot 7$ \\
\hline $17-$ & 693 & $75 \cdot 6$ & $72 \cdot 3$ & 681 & 80.6 & 78.6 & 1,374 & $78 \cdot 1$ & $76 \cdot 0$ \\
\hline $18-$ & 333 & $79 \cdot 8$ & $79 \cdot 5$ & 51 & $70 \cdot 6$ & $68 \cdot 6$ & 384 & $78 \cdot 6$ & $77 \cdot 3$ \\
\hline
\end{tabular}

Note: Those Junior Leaders remaining in the unit during their 18th year are probably unrepresentative of the group; as a rule Junior Leaders proceed to man service on their 18th birthday and those remaining are either taking special examinations, or have been late arrivals, or have been retarded through illness, etc.

TABLE IV

HABITS OF REGULAR SMOKERS

\begin{tabular}{|c|c|c|c|c|c|c|c|c|c|c|c|c|c|c|}
\hline \multirow{3}{*}{ Age (yrs) } & \multicolumn{2}{|c|}{$\begin{array}{l}\text { Number in } \\
\text { Age Group }\end{array}$} & \multirow{2}{*}{\multicolumn{5}{|c|}{ 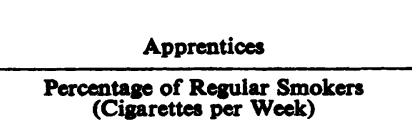 }} & \multicolumn{2}{|c|}{$\begin{array}{l}\text { Number in } \\
\text { Age Group }\end{array}$} & \multirow{2}{*}{\multicolumn{5}{|c|}{$\frac{\text { Junior Leaders }}{\text { Cigarettes per Week) }}$}} \\
\hline & \multirow{2}{*}{ Total } & \multirow{2}{*}{$\begin{array}{l}\text { Regular } \\
\text { Smokers }\end{array}$} & & & & & & \multirow{2}{*}{ Total } & \multirow{2}{*}{$\begin{array}{l}\text { Regular } \\
\text { Smokers }\end{array}$} & & & & & \\
\hline & & & $1-4$ & $5-9$ & $10-19$ & $20-39$ & $40+$ & & & $1-4$ & $5-9$ & $10-19$ & $20-39$ & $40+$ \\
\hline $15-$ & 345 & 187 & 13.9 & $17 \cdot 1$ & $21 \cdot 4$ & 26.7 & $20 \cdot 3$ & 431 & 266 & 10.7 & $13 \cdot 2$ & 28.6 & 28.9 & $18 \cdot 4$ \\
\hline $16-$ & 693 & 488 & $4 \cdot 1$ & 6.9 & $17 \cdot 0$ & $33 \cdot 0$ & $38 \cdot 1$ & 825 & 620 & $4 \cdot 2$ & 10.5 & 16.9 & $27 \cdot 2$ & 45.0 \\
\hline $17-$ & 693 & 524 & 3.6 & 4.4 & $10 \cdot 7$ & 19.8 & 61.0 & 681 & 549 & 1.6 & 4.0 & $9 \cdot 1$ & 26.0 & 59.2 \\
\hline $18-$ & 333 & 266 & 1.5 & $1 \cdot 1$ & 4.9 & 10.9 & 81.6 & 51 & 36 & $2 \cdot 8$ & $\overline{0}$ & 2.8 & 19.4 & $75 \cdot 0$ \\
\hline
\end{tabular}


one to nine per week. This is more marked in the Apprentices than the Junior Leaders, but it seems to indicate that during the 17th year those who are smokers become confirmed in the habit, and that from then on the great majority smoke more than twenty per week.

As one would expect, this increase in consumption continues with successive age groups and by the age of 18 the percentage of regular smokers who are in the " 40 plus" category had risen to 81 per cent. for the Apprentice and 75 per cent. for Junior Leadersalthough as noted in Table III the number of Junior Leaders remaining at this age are too few for statistical accuracy and may well be unrepresentative of the group. It would seem that by age 18 the adult pattern and habit had been achieved-it might be of interest to ascertain at this age the extent of the "plus" in the " 40 plus"!

\section{Discussion}

In a survey such as this, especially in military units with "No Smoking" rules for those under 17, it is essential to ensure complete anonymity in order to get truthful answers. For this reason the survey was conducted by either the Medical or the Education Officer and the questionnaires were sealed in one envelope in the presence of the boys as soon as completed-this fact was impressed on all before the start of the questioning.

There is no doubt that any questionnaire which demands answers from memory is open to errorboth voluntary and involuntary; in order to assess the accuracy of the replies received, a portion of one Apprentice unit (86 in number) was questioned 4 months before the general survey and then requestioned with the rest of the unit. Analysis of these answers showed that, although for individuals there is a large margin of error in the answers given, there being evidence that these errors are larger where the memory span exceeds 8 years, there appears to be little difference between the first and second set of answers. It can be taken that the questionnaire method as operated for this survey is capable of allowing valid conclusions to be drawn.

It is not easy to make a direct comparison of these results with other work done in this field. The survey carried out by the London School of Hygiene and Tropical Medicine was concerned mainly with children below the age of 15 . Just on 40 per cent. of the Norwegian school children surveyed by Nilsen were over 15 , but he adopted a somewhat different method of classifying degrees of smoking. However, if his "daily smokers" are equated to our "regular smokers", there is broad agreement, especially with regard to the importance of the sudden increase in smoking in the 17th year and the increasing consumption with age in addition to increased frequency of smoking. There is a significant difference in the percentages of daily (regular) smokers recorded by Nilsen, which are very much less than we found in the young soldiers, his figures were 35 per cent. at 17 and 38 per cent. at 18 compared with our comparable average levels (smoking five or more per week) of 76 per cent. and $77 \cdot 3$ per cent. at those ages.

The Tobacco Manufacturers in their Standing Committee Research Papers classified individuals as non-smokers, and smokers of less than ten or more than ten cigarettes per week, and they give figures for each age group. From their figures it is apparent that, in whatever way the comparison is made, the rate of smoking in their subjects was considerably less than that found in Army boys, and whilst strict comparison is not possible owing to the different criteria adopted it would appear that the higher level of smoking in the Army boys is of the order of 17 to 20 per cent. for all age groups between 15 and 18 years. The Tobacco Manufacturers survey also confirmed the fact that the critical age seems to be 16; it was at the age of 16 in their series, too, that the greatest increase in the smoking habit occurred.

It would seem that some general agreement is now required on what constitutes a regular smoker, if only to assist comparison of the results of different surveys. Although we have used the two criteria of "more than one cigarette per week" and "more than five cigarettes per week", we now consider the latter to be the best definition of a regular smoker and this is roughly equivalent to one per day or the "daily smoker".

This survey of young soldiers confirms the previous work with regard to the age of first starting to smoke and the onset of regular smoking, but with this new opportunity for a full-scale study of the age groups 15 to 18 , the importance of the 17th year has become apparent, for it is in this year that the smoking habit seems to crystalize and become fixed. We would agree with Nilsen that any programme of health education should begin at 13 and continue till about 18 , but would go further than this and say that the greatest effort should be made towards the 15- and 16-year-old, for if we can prevent the habit getting set at this age we may well lay the foundations for its repression or even abandonment. With regard to our special concern-the Army boy-we have found that because they smoke more than their civilian counterpart the need for their education is even greater and that, to be successful, it should be given before they reach the age of 17 . It should in fact be concentrated into the first 2 years of their service with possibly some follow up or consolidation later. 
SUMmaRY AND CONCLUSIONS

(a) A survey was carried out of the smoking habits of young soldiers. The primary aim was to ascertain whether knowledge of the pattern of their smoking habit could assist or improve the efficiency of a programme of health education; a subsidiary aim was the establishment of a basis for future assessment of the efficacy of such a programme.

(b) A questionnaire was completed by 4,381 young soldiers between the ages of 15 and 18 years. These age groups have formed less than 5 per cent. of previous surveys in the United Kingdom, but have been surveyed in Norway and have been investigated to some extent by the Tobacco Manufacturers.

(c) The young soldiers were either Apprentices learning a skilled trade, or Junior Leaders training for regimental duties.

(d) It was found that the smoking habits of these boys before joining the Army were similar to those of school children as reported in previous surveys.

(e) At the start of their service at 15 years of age, regular smoking was the habit of more than 50 per cent. of the boys, this rose to 79 per cent. during their service, the latter level being reached by Junior Leaders in their 18th and Apprentices in their 19th year. Junior Leaders smoked more than Apprentices but only to the extent of 5 to 8 per cent. at any given time.

( $f$ ) The increase in the rate of smoking was not uniform. The greatest increase occurred during the 17 th year when it was of the order of 15 to 20 per cent., thereafter increasing by only 5 to 7 per cent. in any one year.

$(g)$ In the 17th year, too, there was a marked change of habit regarding the number of cigarettes smoked. In this year, the adult habit of the confirmed smoker appears, and there is a virtual disappearance of the less than ten per week smoker. The increase in forty + smokers rises steadily until at age 18 the full adult pattern has been achieved with up to 81 per cent. of the smokers in this group.

(h) In the 17th year, and subsequently, the difference between the two critera used to assess regular smoking "one or more cigarettes per week" and "five or more cigarettes per week" became negligible.

(i) Comparison has been made with the results of a survey conducted by Nilsen; there was broad agreement with regard to the sharp increase which occurred in the 17th year but the percentage of regular smokers in our young soldiers was much higher than in his Norwegian school children.

(j) In a comparison with figures given by the Tobacco Manufacturers, it was found that more Army boys are regular smokers than their civilian counterparts, the excess seeming to be of the order of 17 to 20 per cent.

(k) It is suggested that one single criterion should be adopted for the categorization of a "regular smoker". Although it differs from our original selection we now favour a level of "more than five cigarettes per week" which can be equated to the "daily smoker".

We should like to thank the Director General Army Medical Services for permission to publish this Paper and AMD (Stats) for their help, particularly Mr. G. Taylor of that Department. Acknowledgement is also due to Mr. S. P. W. Chave and the Study Group of the London School of Hygiene and Tropical Medicine for allowing us to model our questionnaire on that used by them.

\section{REFERENCES}

Bothwell, P. W. (1959). Med. Offr, 102, 125.

Chave, S. P. W., Schilling, R. S. F., and others (1959). Brit. J. prev. soc. Med., 13, 1.

Jones, A. Parry (1957). Lancet, 1, 631.

Nilsen, E. (1959). Brit. J. prev. soc. Med., 13, 5.

Raven, R. W. (1957). Lancet, 1, 1139.

Todd, G. F. (1959). Tobacco Manufacturers' Standing Committee. Research Papers No. 1: "Statistics of Smoking", 2nd ed., London. 